\title{
Outcomes of intra-amniotic injection of ethacridine lactate for pregnancy termination in the third trimester or pregnancy termination in women with prior cesarean section
}

\section{Fangfang Lu}

Guilin Medical University Affiliated Hospital

\section{Wenjun Tang}

Affiliated Hospital of Guilin Medical University https://orcid.org/0000-0003-0306-5865

Wanchao Wang

Guilin Medical University Affiliated Hospital

\section{Guiyan Tang}

Guilin Medical University Affiliated Hospital

\section{Xin Huang}

Guilin University of Aerospace Technology

Jianghua Le ( $\sim 1019953306 @ q q . c o m$ )

Guilin Medical University Affiliated Hospital

Kai Li (D1007640062@qq.com)

Affliated Hospital of Guilin Medical University

Research article

Keywords: Ethacridine lactate, Cesarean section, Third trimester, Termination pregnancy

Posted Date: April 9th, 2020

DOI: https://doi.org/10.21203/rs.3.rs-19936/v1

License: (c) (i) This work is licensed under a Creative Commons Attribution 4.0 International License. Read Full License 


\section{Abstract}

Background: This study aimed to evaluate the safety and efficacy of the intra-amniotic injection of ethacridine lactate in third trimester pregnancy patients and in patients with a history of cesarean section to induce labor.

Methods : This retrospective clinical investigation analyzed 270 patients who underwent second or third trimester pregnancy termination at the affiliated hospital of Guangxi Guilin Medical University between January 1, 2017 and February 29, 2020, including those with and without cesarean section histories. Clinical characteristics and outcomes of all patients were analyzed following treatment with ethacridine lactate.

Results: A total of 270 patients were hospitalized for pregnancy terminations, including 234 patients in a second trimester group, 36 patients in a third trimester group, 209 patients in a non-cesarean section group, and 61 patients in a cesarean section group. Among the 270 patients studied, five had twin pregnancies, and eight had two previous cesarean sections. All the included cases had successful vaginal delivery. There was no significant difference in prenatal and postpartum hemoglobin, incidence of massive hemorrhage, the rate of residual placenta and membranes, manual removal of placenta, uterine curettage,and blood transfusion between the second and third trimester groups $(P>0.05)$, as well as between the non-cesarean and cesarean section groups $(P>0.05)$. The abortion interval $(A I)$ in the second trimester group was longer than that in the third trimester group $(P=0.014)$, and the hemorrhage of delivery in the third trimester group was significantly higher than in the second trimester group $(P=0.019)$. The hemorrhage of delivery in the cesarean section group was higher than that in the noncesarean section group but displayed no significant difference $(P>0.05)$. No uterine rupture and placental abruption occurred in any of the patients.

Conclusions : Intra-amniotic injection of ethacridine lactate demonstrated good clinical effects and could be used as a suitable method for third trimester pregnancy termination or pregnancy termination in women with prior cesarean sections, and it can also be used to induce labor in the second trimester for twin pregnancies and in patients with a history of two cesarean sections.

\section{Introduction}

With the expansion of indications for cesarean section and improvement of obstetric operation skills, global cesarean section rates have gradually increased in recent years, including in China, where it has increased to $46 \%$ in the past decade ${ }^{[1,2]}$. Approximately $30 \%$ of all cesarean section cases were repeat operations. Therefore, the number of women with a history of single or even multiple cesarean sections who have undergone pregnancy termination has also increased. Previous studies have discovered that women with a history of cesarean section have a higher risk of uterine rupture during pregnancy termination in the second or third trimester ${ }^{[3-5]}$. Although the majority of pregnancy terminations are performed in the first trimester, termination during the second trimester accounts for approximately 10- 
$15 \%$ of abortions performed worldwide ${ }^{[6]}$. In China, approximately $5 \%$ of pregnancy terminations are performed in the second trimester ${ }^{[7]}$. The risk of pregnancy termination increases gradually with the number of pregnant weeks. The reasons for pregnancy termination include fetal abnormality, intra-uterine fetal death (IUFD), unplanned pregnancy, and serious maternal complications. Due to developments in molecular biology and ultrasound technology, most fetal abnormalities can be detected early or during the second trimester and terminated on time. In some areas where medical resources are absent, gestational women also have rare antenatal care visits. Thus, their fetal abnormalities are often detected in the third trimester, so they have to risk pregnancy termination in the third trimester.

Many methods of second trimester pregnancy termination have been proposed in recent years. These include oral or vaginal misoprostol, mifepristone combined with misoprostol, extra-amniotic administration of ethacridine lactate, and balloon insertion ${ }^{[7,8]}$. The efficacy and safety of these methods have been assessed in many research studies. Ethacridine lactate has been the most common method of second-trimester abortion in China since $1970^{[9]}$. It stimulates endogenous prostaglandins and thromboxane production, probably by provoking a chemical trauma to the fetal membranes and the deciduas. Thus, promoting cervical priming and labor initiation ${ }^{[10]}$. Currently, attention is being paid to the therapeutic effect of ethacridine lactate used in combination with other drugs on patients during midtrimester labor induction. Mei et al. ${ }^{[11]}$ reported that ethacridine lactate used in combination with mifepristone may significantly improve outcomes in second trimester pregnancy termination without increasing complications, and they recommended it as a suitable choice for moderate gestation induced labor. Nevertheless, studies examining the safety and efficacy of using ethacridine lactate alone in women with prior cesarean deliveries or in women undergoing third trimester-induced labor are limited. In our study, we retrospectively investigated outcomes in patients with a history of cesarean section and in patients in the third trimester of pregnancy after induction of labor with ethacridine lactate. The purpose of the report was to evaluate the safety and efficacy of intra-amniotic injection of ethacridine lactate for medical abortion in women with prior cesarean deliveries and in women in the third trimester .

\section{Methods}

Approved by the hospital's ethics committee, this retrospective clinical investigation analyzed 270 women who underwent second or third trimester pregnancy termination at the affiliated hospital of Guangxi Guilin Medical University from January 1, 2017 and February 29, 2020. Patients of gestational age ranging from $13+2$ to $40+5$ weeks and who had a history of cesarean section were included in our study, including eight patients with a history of second cesarean section and five patients with twin pregnancies. Patients were clearly informed of their treatment modalities and provided signed consent prior to their intervention. Patient data were collected through archived medical records. Clinical characteristics, such as maternal age, gravidity, parity, gestational weeks, previous cesarean delivery history, reproductive history, and indications for termination of pregnancy, were reviewed. Patients who could not be followed-up on time were excluded from the study. Based on gestational weeks, all patients were assigned to two groups: the second trimester group (approximately $13+2$ weeks to $27+6$ weeks) and 
the third trimester group (approximately 28 weeks to $40+5$ weeks). Furthermore, based on patient history of cesarean sections, all patients were assigned to two groups: the cesarean section group and the noncesarean section group.

\section{Intra-amniotic injection of ethacridine lactate}

All patients were hospitalized for treatment. An amniocentesis injection of $100 \mathrm{mg}$ of ethacridine lactate (rivanol) was administered to enrolled patients after verifying the absence of liver and kidney disease. For patients with gestational age over 30 weeks and the fetus was still alive, intracardiac injection of $5 \mathrm{ml}$ of potassium chloride into the fetus heart was performed before amniocentesis until the fetal heart stopped. Patients then delivered in the following 12 to $72 \mathrm{~h}$. A second $100 \mathrm{mg}$ of ethacridine lactate was given for patients displaying no regular contractions $72 \mathrm{~h}$ after injection. After delivery of the placenta, placenta integrity and fetal membranes were examined by an experienced midwife. In cases of profuse bleeding, blood transfusion was undertaken. If placenta adhesion or retention occurred, manual removal of the placenta was implemented. After approximately 1 to 4 weeks of fetal discharge, all patients underwent ultrasound testing to reconfirm the absence residual placental membrane. If there was placenta residue, uterine curettage was implemented.

\section{Analysis of outcomes}

Prenatal and postnatal hemoglobin $(\mathrm{Hb})$ values were recorded for all patients. After treatment with ethacridine lactate, Al, hemorrhage of delivery, rate of uterine rupture, placental abruption, residual placenta and membranes, and massive haemorrhage were calculated in each group. The number of cases that underwent uterine curettage, manual removal of the placenta, and blood transfusion were recorded. Hospital stays were also calculated. Al was calculated from the time of ethacridine lactate injection to the time of fetal delivery. Blood loss was quantified using standard collect plates during vaginal deliveries. Massive hemorrhage was defined as blood loss of $500 \mathrm{ml}$ or more. In addition, we analyzed the outcomes of patients with two cesarean sections as well as patients with twin pregnancies.

\section{Statistical analysis}

SPSS 16.0 statistical software (IBM Corp., Armonk, NY, USA) was used to process all data. Independent sample $t$-test was used to compare the measurement data between two groups. Counting data comparison of two groups was evaluated using chi-square test and Fisher's exact test. Descriptive statistics were provided in the form of standard deviations of means, frequencies, and percentages. A value of $P<0.05$ was defined as statistically significant.

\section{Results}

A total of 270 patients were hospitalized for pregnancy terminations, including 205 cases of fetal birth defect, 35 cases of IUFD, 14 cases of pregnancy complications, 14 cases of unplanned pregnancy, and 2 cases of other causes. There were 234 patients in the second trimester group, 36 patients in the third 
trimester group, 209 patients in the non-cesarean section group, and 61 patients in the cesarean section group.

Table 1 shows the clinical characteristics of patients in the second trimester group and the third trimester group. The average gestational age in the second trimester group was $22.03 \pm 3.45$ weeks, and in third trimester group, it was $32.04 \pm 2.95$ weeks. The difference was statistically significant $(P<0.001)$. No significant difference was observed in maternal age, gravidity, parity, and reproductive history in both groups $(P>0.05)$. We then analyzed the outcomes of the two groups after treatment with ethacridine lactate. As shown in Table 2, Al in the second trimester group and the third trimester group was $42.84 \pm 13.35 \mathrm{~h}$ and $37.05 \pm 11.23 \mathrm{~h}$ respectively, and the difference was statistically significant $(P=0.014)$. The shortest Al was $12.78 \mathrm{~h}$ in the second trimester group and $12.00 \mathrm{~h}$ in the third trimester group. The hemorrhage of delivery was $161.58 \pm 108.86 \mathrm{ml}$ in the second trimester group, and it was less in the third trimester group, $(215.28 \pm 210.20 \mathrm{ml} ; \mathrm{P}=0.019)$. In the second trimester group, prenatal and postpartum hemoglobin was $113.21 \pm 12.03 \mathrm{~g} / \mathrm{L}$ and $106.53 \pm 11.51 \mathrm{~g} / \mathrm{L}$, respectively. The difference was not statistically significant compared with the third trimester group $(P>0.05)$. In addition, incidence of massive hemorrhage in the second trimester group and the third trimester group was $2.99 \%(7 / 234)$ and $2.78 \%(1 / 36)$, respectively. There was no significant difference in incidence of massive hemorrhage between the two groups $(P>0.05)$. The maximum hemorrhage was $700 \mathrm{ml}$ in the second trimester group and $1,400 \mathrm{ml}$ in the third trimester group. One patient in the third trimester group had massive blood loss of $1,400 \mathrm{ml}$ duo to uterine atony and was subjected to transfusion. Another patient with low hemoglobin level $(68 \mathrm{~g} / \mathrm{L})$ in the second trimester group also received blood transfusion. Furthermore, no significant difference was observed in hospital stays, the levels of residual placenta and membranes, manual removal of placenta, uterine curettage, and blood transfusion between groups $(P>0.05)$. No uterine rupture and placental abruption occurred in any of the patients.

Furthermore, the outcomes after treatment with ethacridine lactate in patients with cesarean section in the second and third trimester of pregnancy were analyzed in. The clinical characteristics of the noncesarean section and cesarean section groups are depicted in Table 3. The gestational weeks in the noncesarean section and cesarean section groups were $23.33 \pm 4.09$ and $23.49 \pm 4.52$ weeks, respectively, and the difference was not statistically significant $(P>0.05)$. However, in the non-cesarean section group, average maternal age was $30.58 \pm 5.75$ years, average gravidity was $2.28 \pm 1.17$, and average parity was $0.54 \pm 0.63$. These values were lower than those of the corresponding cesarean section group $(P<0.001)$. The reason for this difference could be explained by the fact that the non-cesarean section group included young patients who had never given birth. Table 4 shows the outcomes of both groups after ethacridine lactate treatment. The $\mathrm{Al}$ in the non-cesarean section group was $41.83 \pm 13.36 \mathrm{~h}$, and $42.85 \pm 12.77 \mathrm{~h}$ in the cesarean section group, with no significant difference $(P>0.05)$. Hemorrhage of delivery was $162.01 \pm 128.35 \mathrm{ml}$ in the non-cesarean section group and $191.80 \pm 124.45 \mathrm{ml}$ in the cesarean section group; the blood loss in the cesarean section group was higher than that in the non-cesarean section group, with no significant difference $(P>0.05)$. Incidence of massive hemorrhage in the noncesarean section group and cesarean section group was 2.39\% (5/209) and 4.92\% (3/61), respectively. The maximum blood loss was $1,400 \mathrm{ml}$ in the non-cesarean section group and $700 \mathrm{ml}$ in the cesarean 
section group. There was no significant difference in the incidence of massive hemorrhage between the two groups $(P>0.05)$.

In the non-cesarean section group, prenatal and postpartum hemoglobin was $113.43 \pm 12.52 \mathrm{~g} / \mathrm{L}$ and $107.43 \pm 12.11 \mathrm{~g} / \mathrm{L}$, respectively, whereas in the cesarean section group, it was $112.52 \pm 10.88 \mathrm{~g} / \mathrm{L}$ and $104.43 \pm 11.79 \mathrm{~g} / \mathrm{L}$, respectively. The hemoglobin change was no different in the two groups $(P>0.05)$. In addition, the difference between hospital stays, the rate of residual placenta and membranes, manual removal of placenta, uterine curettage, and blood transfusion in both groups were not statistically significant $(P>0.05)$. No uterine rupture and placental abruption occurred in any of the patients.

Among the 270 patients studied, five were cases of twin pregnancy $(5 / 270,1.85 \%)$, and eight had two previous cesarean sections $(8 / 270,2.96 \%)$. They were all in their second trimester. In addition, another eight patients in their third trimester had one previous cesarean section $(8 / 270,2.96 \%)$. Their clinical features and outcomes are displayed in Table 5, Table 6, and Table 7, respectively. Table 5 shows that average gestational age and hemorrhage of delivery of all patients with twin pregnancies were $23.78 \pm$ 2.90 weeks and $240.00 \pm 114.02 \mathrm{ml}$, respectively. Only Patient 1 required manual removal of the placenta followed by uterine curettage, due to placental adherence. Massive haemorrhage and blood transfusion did not occur in all twin pregnancy cases. Among patients who had two previous cesarean sections, the average gestational age and hemorrhage of delivery was $21.47 \pm 4.87$ weeks and $205.00 \pm 152.13 \mathrm{ml}$, respectively, and except for Patient 13 who had blood loss of $550 \mathrm{ml}$, none required blood transfusion. Patient 12 underwent the manual removal of the placenta due to placenta adhesion, Patient 8 underwent uterine curettage because of placenta remnants (Table 6). The average gestational age and hemorrhage of delivery of all patients with one previous cesarean section was $31.26 \pm 2.25$ weeks and $188.75 \pm 38.71$ $\mathrm{ml}$, respectively (Table 7). Only Patient 15 underwent manual removal of the placenta due to placenta adhesion, and no massive hemorrhage or blood transfusion occurred in any of the patients.

\section{Discussion}

As early as 1949, researchers reported the use of ethacridine lactate for pregnancy termination ${ }^{[12]}$. Subsequently, ethacridine lactate has been widely used around the world to terminate pregnancy in the second trimester due to its favorable price and obvious therapeutic effects, especially in developing countries. In China, ethacridine lactate is currently the first-line method for second trimester pregnancy termination ${ }^{[13]}$. Ethacridine lactate belongs to the acridine dye group, was a weak base with antibacterial effect. Parkington et al. ${ }^{[14]}$ found that ethacridine lactate stimulated uterine contraction by activating uterine mast cells and inducing the release of contractile and proinflammatory mediators for parturition. Although intra-amniotic injection of ethacridine lactate was an invasive operation, no toxic side effects have been reported in clinical practice ${ }^{[7]}$.

The efficacy and safety of ethacridine lactate used alone or combined with other drugs for second trimester pregnancy termination has been widely investigated ${ }^{[15,16]}$. Mei et al. ${ }^{[17]}$ reported that mifepristone in combination with ethacridine lactate used to induce abortion of second trimester 
pregnancies could reduce blood loss and shorten Al without increasing complications. However, research investigating using ethacridine lactate alone for third trimester pregnancy termination remains rare. In our study, we first divided the patients into a second trimester group and a third trimester group, according to gestational age. Compared with the second trimester group, there were no significant differences in regard to hospital stays, prenatal and postpartum hemoglobin, incidence of massive hemorrhage, the rate of residual placenta and membranes, manual removal of placenta, uterine curettage,and blood transfusion in the third trimester group $(P>0.05)$. However, a significant difference was observed in $\mathrm{Al}$ and hemorrhage of delivery between the two groups. The Al in the second trimester group was longer than that in the third trimester group $(P=0.014)$. This was mainly because the third trimester group had increased uterine sensitivity, and they displayed greater response sensitivity to ethacridine lactate. It has been reported that uterine muscle excitability increases throughout the third trimester of pregnancy, and the increase in excitability was supported by a gradual reduction in the cytoplasmic membrane negativity of smooth muscle cells, which increased the probability that voltage-operated calcium channels would be in the open and conducting configuration ${ }^{[18]}$.

In our study, the hemorrhage of delivery of patients in the third trimester was significantly higher than those in the second trimester $(P=0.019)$. With an increase in gestational weeks, the blood flow from the uterus and placenta also increased gradually. Thus, bleeding risk was higher in those who terminated their pregnancy in the third trimester than in those who terminated their pregnancy in the second trimester. All enrolled patients successfully delivered vaginally after intra-amniotic injection of ethacridine lactate, and no uterine rupture and placental abruption occurred in any of the patients. In addition, of the 270 enrolled patients, five second trimester patients were twin pregnancy cases. However, only a few studies have examined methods of labor induction suitable for twin pregnancy in second trimester pregnancies. Therefore, our findings should be confirmed by more extensive investigations. All results indicate that intra-amniotic injection of ethacridine lactate is effective and relatively safe for terminating pregnancies in the third trimester and may be used as a method of clinical treatment. In addition, this method can also be used to induce labor in the second trimester of twin pregnancies under the premise of informed choice.

Although some researches have confirmed that ethacridine lactate was safe for patients without cesarean section history during second trimester termination ${ }^{[11,17]}$, little is known about the feasibility of using ethacridine lactate alone for termination of pregnancy in women with prior cesarean section. Chen et al. ${ }^{[19]}$ reported that bleeding for second-trimester pregnancy termination via mifepristone and ethacridine lactate in patients without history of cesarean section $(72.12 \pm 44.0 \mathrm{ml})$ was less than those with prior cesarean sections $(111.93 \pm 118.2 \mathrm{ml}, \mathrm{P}<0.05)$, and no significant difference was found in Al, hospital stay, rate of hemorrhage, and transfusion in any of the patients. This indicated that mifepristone combined with ethacridine lactate was safe and effective for patients with prior cesarean undergoing second trimester pregnancy termination. In our study, all patients were then divided into two groups based on cesarean section history: the cesarean section group and the non-cesarean section group. Similar to previous studies, we found that Al, prenatal and postpartum hemoglobin, hospital stays, 
incidence of massive hemorrhage, levels of residual placenta and membranes, manual removal of placenta, uterine curettage, and blood transfusion did not display any significant difference between the two groups $(P<0.05)$. It is worth noting that although no significant difference in hemorrhage of delivery was found between the two groups, the blood loss in the cesarean section group was greater than that in the non-cesarean section group. These results suggest that a scarred uterus is associated with a higher risk of bleeding compared to a non-scarred uterus during labor induction. Of all cesarean section patients, eight were in the second trimester and with two previous cesarean sections (the interval between two operations ranged from two years to nine years), and eight cases were in the third trimester and with single previous cesarean section (the interval of previous cesarean section ranged from two years to fourteen years). No uterine rupture and placental abruption occurred in any of the patients. Despite the fact that uterine rupture did not occur in any of the cases in our study, the inherent risk of uterine rupture in patients with prior cesarean sections undergoing labor induction should not be ignored. Reports have indicated that the risk of uterine rupture in women with prior cesarean delivery was $4.5 \%(3 / 66)$ during the second trimester termination of pregnancy ${ }^{[20]}$. Sumalatha et al. ${ }^{[21]}$ reported the risks of severe obstetric complications, such as uterine rupture, increased with increasing numbers of previous cesarean sections. Uterine rupture in women with prior cesarean delivery was $0.6 \%$, and the risk of uterine rupture in women with two previous cesarean sections was $1.6 \%$. Therefore, attention should be paid to the risk of uterine rupture and hemorrhage in women with scarred uteruses during pregnancy termination, especially those who have a history of two or more cesarean sections. In clinical practice, they should be supported to make informed decisions, regarding methods of pregnancy interruption. The above results indicated that intra-amniotic injection of ethacridine lactate was relatively safe and effective for women with prior cesarean in second and third trimester pregnancy termination. In addition, intra-amniotic injection of ethacrine lactate may be used with caution for second trimester termination in patients with two cesarean sections under close monitoring for uterine rupture and massive hemorrhage.

Our study included a few shortcomings, including its retrospective nature and limited sample size, possibly leaving results open to bias. The numbers of patients with twin pregnancies, second trimester patients with two cesarean sections, and third trimester patients with one cesarean section were not enough, and without follow-up studies, we cannot draw definite conclusions about the efficacy of ethacridine lactate. Furthermore, the assessment of blood loss may be inaccurate. In addition, due to the lack of comparison with other treatments, we could not fully assess if ethacridine lactate alone was superior to other combined treatments. Future studies with larger multi-center trials are required to confirm the safety and effectiveness of this treatment.

\section{Conclusions}

Intra-amniotic injection of ethacridine lactate demonstrated good clinical effects and can be implemented as a suitable method for third trimester pregnancy termination or pregnancy termination in women with prior cesareans. It can also be used to induce labor in the second trimester of twin pregnancies under the premise of informed choice. In addition, with the patient's full informed consent, intra-amniotic injection 
of ethacrine lactate may be used with caution for second trimester termination in patients with two cesarean sections in combination with close monitoring for uterine rupture and massive hemorrhage.

\section{Abbreviations}

Al:abortion interval;IUFD:intra-uterine fetal death;Hb:hemoglobin

\section{Declarations}

\section{Ethics approval and consent to participate}

The study was approved by the Ethics Committee of Affliated Hospital of Guilin Medical University.All patients provided signed consent prior to the intervention. All patients consented to analysis of their medical records in our manuscript and we obtained the permission from the hospital.

\section{Consent for publication}

We have obtained consent for the publication of personal or clinical details from 270 patients.

\section{Availability of data and material}

We agree to allow the readers and journal to review our primary data if requested.

\section{Competing interests}

We declared that the authors report no conflict of interest.

\section{Funding}

None.

\section{Authors' contributions}

$\mathrm{KL}$ and $\mathrm{JHL}$ contributed to the study design;FFL collected patients' information,performed statistical analysis and drafted the manuscript;WJT collected patients' information,performed statistical analysis;WCW,GYT and XH collected patients' information.All authors have read and approved the manuscript.

\section{Acknowledgements}

None.

\section{References}


[1] A P Betran , M R Torloni , J J Zhang,et al.WHO Statement on Caesarean Section. Rates.BJOG.2016;123 (5):667-670.

[2] Lumbiganon P, Laopaiboon M, Gülmezoglu AM,et al. Method of delivery and pregnancyoutcomes in Asia: The WHO global survey on maternal and perinatalhealth 2007-08. Lancet.2010;375 (9713):490-499.

[3] Boulot P, Hoffet M, Bachelard B.et al.Late vaginal induced abortion after a previous cesarean birth potential for uterine rupture.Gynecol Obstet Invest.1993;36 (2): 87-90.

[4] Atienza MF, Burkman R, King T. Midtrimester abortion induced by hyperosmolar urea and prostaglandin $\mathrm{F} 2 \mathrm{a}$ in patients with previous cesarean section: clinical course and potential for uterine rupture. Am J Obstet Gynecol.1980;138:55-59.

[5] Dickinson JE. Misoprostol for second-trimester pregnancy termination in women with a prior cesarean delivery. Obstet Gynecol.2005;105 (2):352-356.

[6] Newmann SJ, Dalve-Endres A, Diedrich JT, et,al. Cervical preparation for second trimester dilation and evacuation. Cochrane Database Syst Rev8:2010;CD007310.

[7] Hou SP, Fang AH, Chen QF, et al. Termination of second-trimester pregnancy by

mifepristone combined with misoprostol versus intra-amniotic injection of ethacridine lactate (rivanol): a systematic review of Chinese trials.Contraception.2011;84(3): 214-223

[8] E G Yapar, S Senöz, M Urkütür,et al. Second trimester pregnancy termination including fetal death:comparison of five different methods. Eur J Obstet Gynecol Reprod Biol.1996;69(2):97-102.

[9] Lu ZL, editor. Family planning theory and practice. Guangzhou, P. R.China: Guangdong Science \& Technology Press; 1988. p. 325.

[10] Cao ZY, editor. Chinese obstetrics and gynecology. Peking, P. R.China: People's Medical Publishing House; 2004. p. 2854-2855.

[11] Quan Mei, XiaoLan Li, HaiJuan Liu,et al.Effectiveness of mifepristone in combination with ethacridine lactate for second trimester pregnancy termination.Eur J Obstet Gynecol Reprod Biol.2014;178: 12-15.

[12] Kashiwara N, Fujibayashi Y.Interruption of pregnancy by extra-ovular instillation of a solution. Sanfu, Shinpo.1949;1: 24.

[13] Hou S, Chen Q, Zhang L, et al. Mifepristone combined with misoprostol versus intra-amniotic injection of ethacridine lactate for the termination of second trimester pregnancy: a prospective, open-label, randomized clinical trial. Eur J Obstet Gynecol Reprod Biol. 2010;151:149-153. 
[14] Rudolph MI, De GM, Sepulveda M, et al. Ethodin: pharmacological evidence of the interaction between smooth muscle and mast cells in the myometrium. J Pharmacol Exp Ther.1997;282 (1):256-61.

[15] Sefa Kelekci, Evrim Erdemoglu, Ismet Inan.Randomized study on the effect of adding oxytocin to ethacridine lactate or misoprostol for second-trimester termination of pregnancy.Acta Obstet Gynecol Scand.2006;85 (7):825-829.

[16] YaLing Zhuang, XiuYing Chen, Li,Li Huang.Mifepristone may shorten the induction-to-abortion time for termination of second-trimester pregnancies by ethacridine lactate.Contraception.2012;85 (2): 211214.

[17] Quan Mei,XiaoLan Li, HaiJuan Liu.Effectiveness of mifepristone in combination with ethacridine lactate for second trimester pregnancy termination.Eur J Obstet Gynecol Reprod Biol.2014;178:12-15.

[18] H C Parkington, M A Tonta, S P Brennecke,et al.Contractile activity, membrane potential, and cytoplasmic calcium in human uterine smooth muscle in the third trimester of pregnancy and during labor.Am J Obstet Gynecol.1999;181 (6):1445-1451.

[19] Chunqin Chen, Feikai Lin, Xiaoyun Wang.Mifepristone combined with ethacridine lactate for the second trimester pregnancy termination in women with placenta previa and/or prior cesarean deliveries.Arch Gynecol Obstet.2017;295 (1): 119-124.

[20] Ping Peng, Xin-Yan Liu, Lei Li, et,al.Clinical Analyses of 66 Cases of Mid-trimester Pregnancy Termination in Women with Prior Cesarean.Chin Med J (Engl).2015;128 (4), 450-454.

[21] Sumalatha Narava, Sindhu Chandra Pokhriyal, Sushma Balbir Singh,et al.Outcome of Multiple Cesarean Sections in a Tertiary Maternity Hospital in the United Arab Emirates: A Retrospective Analysis.Eur J Obstet Gynecol Reprod Biol.2020.247:143-148.

\section{Tables}

Table 1 clinical characteristics of the second trimester group and the third trimester group

\begin{tabular}{|c|c|c|c|c|c|c|}
\hline \multicolumn{2}{|c|}{$\begin{array}{l}\text { second trimester } \\
(\mathrm{n}=234)\end{array}$} & \multicolumn{2}{|l|}{$\begin{array}{l}\text { third trimester } \\
\qquad(\mathrm{n}=36)\end{array}$} & \multirow{2}{*}{$\begin{array}{c}t \\
0.41\end{array}$} & \multirow{2}{*}{$\chi^{2}$} & \multirow{2}{*}{$\begin{array}{c}P \\
0.68\end{array}$} \\
\hline rear) & $31.36 \pm 5.60$ & $30.94 \pm 6.00$ & & & & \\
\hline & $2.53 \pm 1.29$ & $2.25 \pm 1.11$ & 1.26 & & $0.21^{\mathrm{a}}$ & \\
\hline & $.69 \pm 0.63$ & $0.58 \pm 0.60$ & 0.93 & & $0.35^{\mathrm{a}}$ & \\
\hline
\end{tabular}

$\begin{array}{lllll}\text { (weeks) } & 22.03 \pm 3.45 & 32.04 \pm 2.95 & 16.48 & 0.00^{\mathrm{a}}\end{array}$

istory

\begin{tabular}{|c|c|c|c|}
\hline n) & 88 & 12 & 0.327 \\
\hline ion(n) & 53 & 8 & \\
\hline & 3 & 16 & \\
\hline
\end{tabular}


${ }^{\mathrm{a}}$ Independent sample t-test.

${ }^{\mathrm{b}}$ Chi-squared test.

Table 2 Outcomes of the second trimester group and the third trimester group after treated with ethacridine lactate

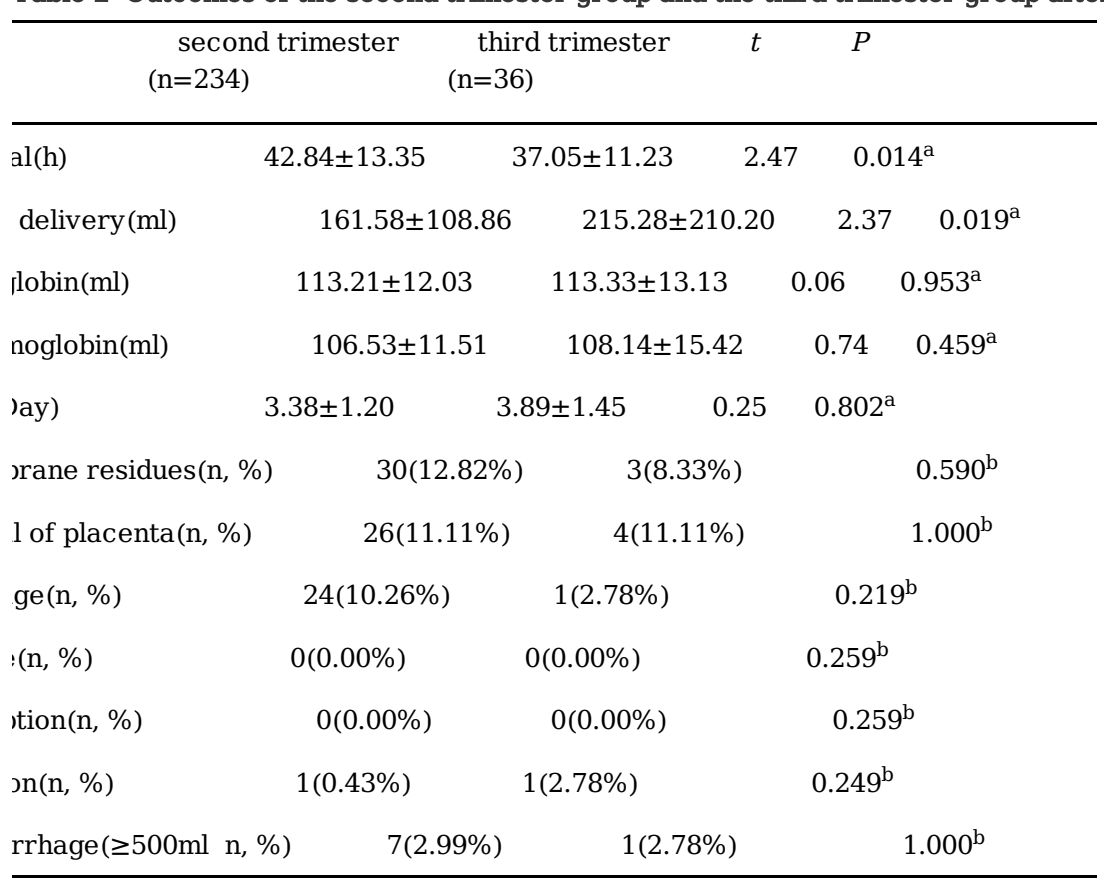

a Independent sample t-test.

b Fisher's exact test.

Table 3 clinical characteristics of the the cesarean section group and the non-cesarean section group

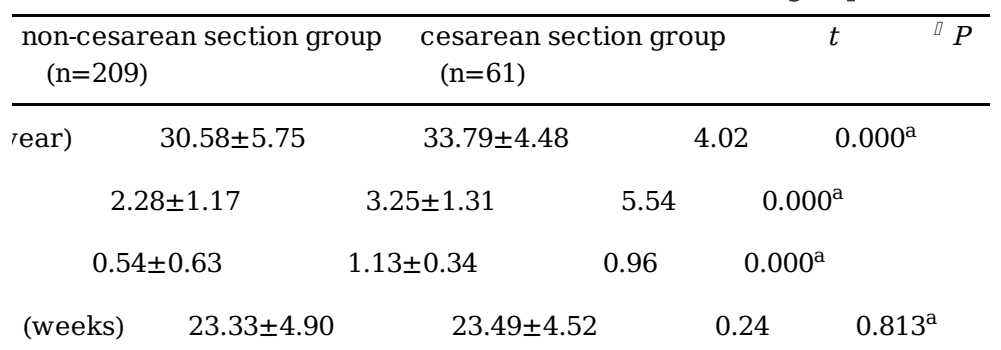

${ }^{\text {a }}$ Independent sample t-test.

Table 4 Outcomes of the the cesarean section group and the non-cesarean section group after treated with ethacridine lactate 


\begin{tabular}{|c|c|c|c|c|c|c|c|}
\hline \multicolumn{3}{|c|}{$\begin{array}{l}\text { non-cesarean section group } \\
\quad(\mathrm{n}=209)\end{array}$} & \multicolumn{3}{|c|}{$\begin{array}{l}\text { cesarean section group } \\
(\mathrm{n}=61)\end{array}$} & $\chi^{2}$ & \multirow[b]{2}{*}{$9^{\mathrm{a}}$} \\
\hline $\mathrm{al}(\mathrm{h})$ & $41.83 \pm$ & 13.36 & $42.85 \pm 12.77$ & 0.5 & \multicolumn{2}{|r|}{$0.599^{\mathrm{a}}$} & \\
\hline delivery(ml) & \multicolumn{2}{|c|}{$162.01 \pm 128.35$} & \multicolumn{2}{|c|}{$191.80 \pm 124.45$} & 1.61 & & $0.109^{a}$ \\
\hline ¡lobin(ml) & \multicolumn{2}{|c|}{$113.43 \pm 12.52$} & \multicolumn{2}{|c|}{$112.52 \pm 10.88$} & 0.51 & \multicolumn{2}{|c|}{$0.611^{\mathrm{a}}$} \\
\hline $\operatorname{noglobin}(\mathrm{ml})$ & \multicolumn{2}{|c|}{$107.43 \pm 12.11$} & \multicolumn{2}{|c|}{$104.43 \pm 11.79$} & 1.71 & \multicolumn{2}{|r|}{$0.080^{\mathrm{a}}$} \\
\hline lay) & \multicolumn{2}{|c|}{$3.79 \pm 1.17$} & $4.00 \pm 1.41$ & 1.15 & \multicolumn{3}{|c|}{$0.206^{\mathrm{a}}$} \\
\hline \multicolumn{2}{|c|}{ Jrane residues(n, \%) } & $25(11.96 \%)$ & \multicolumn{2}{|c|}{$8(13.11 \%)$} & \multicolumn{3}{|c|}{0.06} \\
\hline \multicolumn{2}{|c|}{ l of placenta(n, \%) } & $26(12.44 \%)$ & \multicolumn{2}{|c|}{$5(8.20 \%)$} & \multicolumn{3}{|c|}{0.84} \\
\hline $\operatorname{ge}(\mathrm{n}, \%)$ & \multicolumn{2}{|c|}{$16(7.66 \%)$} & \multicolumn{2}{|l|}{$9(14.75 \%)$} & \multicolumn{3}{|c|}{$2.83 \quad 0.092^{\mathrm{b}}$} \\
\hline$(\mathrm{n}, \%)$ & \multicolumn{2}{|c|}{$0(0.00 \%)$} & \multicolumn{2}{|l|}{$0(0.00 \%)$} & \multicolumn{3}{|c|}{$0.362^{b}$} \\
\hline tion(n, \%) & \multicolumn{2}{|c|}{$0(0.00 \%)$} & \multicolumn{2}{|l|}{$0(0.00 \%)$} & 0.83 & \multicolumn{2}{|c|}{$0.362^{b}$} \\
\hline sn(n, \%) & \multicolumn{2}{|c|}{$2(0.96 \%)$} & $0(0.00 \%)$ & & \multicolumn{3}{|c|}{$1.000^{\mathrm{c}}$} \\
\hline \multicolumn{3}{|c|}{ rrhage $(\geq 500 \mathrm{ml} \mathrm{n}, \%)$} & \multicolumn{2}{|c|}{$3(4.91 \%)$} & \multicolumn{3}{|c|}{$0.386^{\mathrm{c}}$} \\
\hline
\end{tabular}

\footnotetext{
a Independent sample t-test.

b Chi-squared test.

${ }^{\mathrm{c}}$ Fisher's exact test.
}

Table 5 Clinical data and outcomes of the patients with twin pregnancy

\begin{tabular}{|c|c|c|c|c|c|c|c|c|c|c|c|c|c|c|c|}
\hline $\begin{array}{l}\text { Patient } \\
\text { number }\end{array}$ & $\begin{array}{c}\text { Maternal } \\
\text { age } \\
\text { (year) }\end{array}$ & Gravidity & (n) & $\begin{array}{l}\text { Gestational } \\
\text { age } \\
\text { (weeks) }\end{array}$ & $\begin{array}{l}\text { Abortion } \\
\text { interval } \\
\text { (h) }\end{array}$ & $\begin{array}{c}\text { Hemorhage of } \\
\text { delivery } \\
\text { (ml) }\end{array}$ & $\begin{array}{c}\text { Prenatal } \\
\text { hemoglobin } \\
(\mathrm{g} / \mathrm{L})\end{array}$ & $\begin{array}{l}\text { Postpartum } \\
\text { hemoglobin } \\
(\mathrm{g} / \mathrm{L})\end{array}$ & $\begin{array}{c}\text { Hospital } \\
\text { stays } \\
\text { (day) }\end{array}$ & $\begin{array}{l}\text { Placental membrane } \\
\text { residues }\end{array}$ & $\begin{array}{l}\text { Manual removal } \\
\text { of placenta }\end{array}$ & $\begin{array}{c}\text { Uterine } \\
\text { curettage }\end{array}$ & $\begin{array}{l}\text { Uterine } \\
\text { rupture }\end{array}$ & $\begin{array}{l}\text { Placental } \\
\text { abruption }\end{array}$ & $\begin{array}{l}\text { blood } \\
\text { transfusion }\end{array}$ \\
\hline 1 & 22 & 4 & 1 & $21+5$ & 18.00 & 100 & 101 & 100 & 3 & + & + & + & - & - & - \\
\hline 2 & 27 & 3 & 0 & $25+0$ & 17.00 & 400 & 123 & 108 & 2 & - & - & - & - & - & - \\
\hline 3 & 34 & 1 & 0 & $27+3$ & 21.87 & 200 & 104 & 93 & 4 & - & - & - & - & - & - \\
\hline 4 & 38 & 2 & 1 & $21+3$ & 42.72 & 200 & 114 & 106 & 5 & - & - & - & - & - & - \\
\hline 5 & 34 & 3 & 1 & $21+3$ & 39.50 & 300 & 123 & 108 & 5 & - & - & - & - & - & - \\
\hline
\end{tabular}

Table 6 Clinical data and outcomes of the patients with two previous cesarean sections

\begin{tabular}{|c|c|c|c|c|c|c|c|c|c|c|c|c|c|c|c|c|}
\hline $\begin{array}{l}\text { Patient } \\
\text { number }\end{array}$ & $\begin{array}{c}\text { Maternal } \\
\text { age } \\
\text { (year) } \\
\end{array}$ & $\begin{array}{l}\text { Gravidity } \\
\text { (n) }\end{array}$ & $\begin{array}{l}\text { Parity } \\
\text { (n) }\end{array}$ & $\begin{array}{c}\text { Gestational } \\
\text { age } \\
\text { (weeks) }\end{array}$ & $\begin{array}{c}\text { Cesarean section } \\
\text { interval } \\
\text { (year) }\end{array}$ & $\begin{array}{l}\text { Abortion } \\
\text { interval } \\
\text { (h) } \\
\end{array}$ & $\begin{array}{c}\text { Hemorrhage of } \\
\text { delivery } \\
(\mathrm{ml})\end{array}$ & $\begin{array}{c}\text { Prenatal } \\
\text { hemoglobin } \\
(\mathrm{g} / \mathrm{L}) \\
\end{array}$ & $\begin{array}{c}\text { Pospartum } \\
\text { hemoglobin } \\
(\mathrm{g} / \mathrm{L})\end{array}$ & $\begin{array}{c}\text { Hospital } \\
\text { stays } \\
\text { (day) } \\
\end{array}$ & $\begin{array}{l}\text { Placental membrane } \\
\text { residues }\end{array}$ & $\begin{array}{l}\text { Manual removal } \\
\text { of placenta }\end{array}$ & $\begin{array}{l}\text { 1 Uterine } \\
\text { curettage }\end{array}$ & $\begin{array}{l}\text { Uterine } \\
\text { rupture }\end{array}$ & $\begin{array}{l}\text { Placental } \\
\text { abruption }\end{array}$ & $\begin{array}{l}\text { blood } \\
\text { transfusion }\end{array}$ \\
\hline 6 & 34 & 4 & 2 & $25+3$ & $4(2007,2010)$ & 41.75 & 100 & 113 & 110 & 3 & - & - & - & - & - & - \\
\hline 7 & 31 & 3 & 2 & $23+5$ & $2(2013,2015)$ & 51.42 & 200 & 106 & 103 & 4 & - & - & - & - & - & - \\
\hline 8 & 40 & 7 & 2 & $24+6$ & $7(2009,2016)$ & 33.50 & 200 & 106 & 105 & 4 & - & + & - & - & - & - \\
\hline 9 & 30 & 3 & 2 & $25+6$ & $2(2008,2010)$ & 33.50 & 230 & 115 & 112 & 2 & - & - & - & - & - & - \\
\hline 10 & 39 & 5 & 2 & $14+1$ & $9(2005,2014)$ & 52.50 & 80 & 110 & 95 & 7 & - & - & - & - & - & - \\
\hline 11 & 31 & 3 & 2 & $22+2$ & $3(2009,2012)$ & 40.42 & 80 & 94 & 92 & 4 & - & - & - & - & - & - \\
\hline 12 & 41 & 6 & 2 & $15+0$ & $5(2002,2007)$ & 78.05 & 200 & 113 & 105 & 5 & + & - & + & - & - & - \\
\hline 13 & 37 & 3 & 2 & $25+1$ & $2(2012,2014)$ & 58.92 & 550 & 115 & 90 & 5 & - & - & - & - & - & - \\
\hline
\end{tabular}


Table 7 Clinical data and outcomes of the patients in the third trimester with a single cesarean section

\begin{tabular}{|c|c|c|c|c|c|c|c|c|c|c|c|c|c|c|c|c|}
\hline $\begin{array}{l}\text { Patient } \\
\text { number }\end{array}$ & $\begin{array}{l}\text { Maternal } \\
\text { age } \\
\text { (year) }\end{array}$ & Gravidity & Parity & $\begin{array}{c}\text { Gestational } \\
\text { age } \\
\text { (weeks) }\end{array}$ & $\begin{array}{c}\text { Time of previous } \\
\text { cesarean section } \\
\text { (year) }\end{array}$ & $\begin{array}{c}\text { Abortion } \\
\text { interval } \\
\text { (h) }\end{array}$ & $\begin{array}{c}\text { Hemorrhage of } \\
\text { delivery } \\
\text { (ml) }\end{array}$ & $\begin{array}{l}\text { Prenatal } \\
\text { hemoglobin } \\
(\mathrm{g} / \mathrm{L})\end{array}$ & $\begin{array}{l}\text { Postpartum } \\
\text { hemoglobin } \\
(\mathrm{g} / \mathrm{L})\end{array}$ & $\begin{array}{c}\begin{array}{c}\text { Hospital } \\
\text { stays } \\
\text { (day) }\end{array} \\
\end{array}$ & $\begin{array}{l}\text { Placental membrane } \\
\text { residues }\end{array}$ & $\begin{array}{l}\text { Manual removal } \\
\text { of placenta }\end{array}$ & $\begin{array}{r}\text { Uterine } \\
\text { curettage }\end{array}$ & $\begin{array}{l}\text { Uterine } \\
\text { rupture }\end{array}$ & $\begin{array}{l}\text { Placental } \\
\text { abruption }\end{array}$ & $\begin{array}{l}\text { blood } \\
\text { transfusion }\end{array}$ \\
\hline 14 & 32 & 3 & 1 & $31+2$ & $12(2006)$ & 39.95 & 150 & 113 & 110 & 3 & - & - & - & - & - & - \\
\hline 15 & 31 & 2 & 1 & $28+0$ & $2(2016)$ & 35.88 & 150 & 107 & 91 & 4 & - & + & - & - & - & - \\
\hline 16 & 30 & 3 & 1 & $30+3$ & $4(2013)$ & 42.18 & 140 & 109 & 104 & 4 & - & - & - & - & - & - \\
\hline 17 & 34 & 2 & 1 & $32+3$ & $3(2015)$ & 32.42 & 200 & 97 & 97 & 2 & - & - & - & - & - & - \\
\hline 18 & 28 & 4 & 1 & $31+6$ & $3(2015)$ & 26.13 & 220 & 118 & 111 & 7 & - & - & - & - & - & - \\
\hline 19 & 29 & 2 & 1 & $35+3$ & $9(2010)$ & 35.73 & 250 & 110 & 95 & 4 & - & - & - & - & - & - \\
\hline 20 & 37 & 4 & 1 & $29+0$ & $14(2005)$ & 42.93 & 200 & 117 & 106 & 5 & - & - & - & - & - & - \\
\hline 21 & 38 & 2 & 1 & $32+4$ & $10(2009)$ & 29.42 & 200 & 140 & 128 & 5 & - & - & - & - & - & - \\
\hline
\end{tabular}

